\title{
Replacement of Long Lasting Insecticide Treated Nets in Malarious Kebeles of Gida Ayana District, East Wollega Zone, Ethiopia
}

\author{
Geletta Tadele $^{1^{*}}$, Abdi Samuel and Emiru Adeba ${ }^{2}$ \\ ${ }^{1}$ Department of Medical Laboratory Science, College of Medical and Health Sciences, Wollega University, \\ Post Box No: 395, Nekemte, Ethiopia \\ ${ }^{2}$ Department of Public Health, College of Medical and Health Sciences, Wollega University, \\ Post Box No: 395, Nekemte, Ethiopia
}

\begin{abstract}
The main objective of the study was to determine the sustainability of owning and utilization of long lasting insecticide treated nets in malarious kebeles of Gida Ayana District. A communitybased cross-sectional study design was used to investigate the replacement and utilization of long lasting insecticide treated nets (LLINs) in four malarious kebeles of Gida Ayana District. The study was conducted in June, 2013 on randomly sampled 420 households. Data were collected using structured, pretested, interviewer-administered questionnaire and presences of LLINs in sleeping areas were checked. Data analysis was performed using SPSS 20.0 for windows software. Logistic regression analysis was used for determining LLINS ownership and sociodemographic characteristics. $P$ values of less or equal to 0.05 were considered significant. Of the 420 households included in the study, $69.3 \%$ possessed one or more LLINs which are owned primary (for the first time) or replaced (substituting the old bed nets after three years of use). There was no significant association between socio-demographic characteristics of respondents and LLINs owing $(P>0.05)$. Attrition rate of households in LLINs owing was 101(24 $\%)$. Of the 291 households which possessed one or more insecticides, $60.8 \%$ have replaced the LLINs after three years of use. $57.8 \%$ of respondents knew as LLINs need replacement after 3 years of use. 81.3 and $19.7 \%$ of respondent prefer free supply and cost subsidize supply of LLINs for sustainable owing respectively. Of 114 households who have possessed LLINs primarily, $70.2 \%$ have used the LLINs for more than 3 years. Utilization rate of LLINs available in the households the night prior to the study was $64.9 \%$ and in $69.75 \%$ of households LLINs were hanged in sleeping areas. Proportion of pregnant women and under five children slept under LLINs the night preceding the study was 43.1 and $48.4 \%$ respectively. Old, worn out LLINs have been replaced after three years of use to sustain malaria control in the study area. Utilization of LLINs among malaria risk group was low. Every household in malarious kebeles should be included during substituting LLINs. Regular monitoring of household is required from health extension workers to scale-up and sustain utilization of LLINs in malaria control.
\end{abstract} Copyright@2014 STAR Journal. All Rights Reserved.

Article Information Article History:

Received : 04-03-2014

Revised : 26-06-2014

Accepted : 29-06-2014

Keywords:

Long Lasting Insecticide

Treated Nets

Replacement

Utilization

Malaria control

*Corresponding Author:

Geletta Tadele

E-mail:

geletta98@yahoo.com

\section{INTRODUCTION}

Malaria is a major public health problem in Ethiopia; it contributes up to $20 \%$ of under-five deaths, estimated to cause 5-10 million clinical malaria cases each year and accounts for $12 \%$ of outpatient visit and $10 \%$ of health facility admissions (Ethiopian $\mathrm{MOH}, 2004$ and President's malaria Initiative, 2011).

Between 2000 and 2010, malaria mortality rates fell by $26 \%$ around the world. In the WHO African Region the decrease was $33 \%$. During this period, an estimated 1.1 million malaria deaths were averted globally, primarily as a result of a scale-up of interventions (WHO, 2012). LLINs or bed nets have been shown to be the most costeffective prevention method against malaria and are part of WHO's Millennium Development Goals (WHO, 2010). Use of LLINs is one of the Malaria control strategy in
Ethiopia (Ethiopian $\mathrm{MOH}, 2011)$. In Ethiopia, distribution of Insecticide treated nets for the control of malaria was first introduced in 2004 (Ethiopian $\mathrm{MOH}, 2006$ ).

A long-lasting insecticidal net is a factory-treated mosquito net made with netting material that has insecticide incorporated within or bound around the fibres. The net must retain its effective biological activity without re-treatment for at least $20 \mathrm{WHO}$ standard washes under laboratory conditions and three years of recommended use under field conditions (WHO, 2005). If long-lasting bed nets have physical lifespan of 3 years, they are more cost effective compared to the conventional type insecticide treated nets (Anni-Maria et al., 2012). 
Geletta Tadele et al.,

Some studies indicated effective life span of LLINs in different countries as 2 to 3 years in Tanzania (Erlanger et al., 2004), three and four years in Western Uganda (Kilian et al., 2011), in SNNP of Ethiopia an estimated $31.0 \%$ of all nets owned in the previous three years had been discarded by owners, the majority of whom considered the nets too torn, old or dirty (Batisso et al., 2012).

WHO recommended strategy, show that free mass distribution of long-lasting insecticidal nets is a powerful way to quickly and dramatically increase coverage (World Malaria Report, 2005). In Ethiopia, LLINs have been freely supplied to increase possession in malaria endemic areas. Coverage of ITNs has been increased in Ethiopia. National ITN coverage rates increased from 3.4\% in 2005 to $53.3 \%$ in 2007 (Ethiopian $\mathrm{MOH}, 2007$ ). Recent studies indicated an increase in coverage of ITNs in Ethiopia; 62.4\% (Sibhatu et al., 2012), 65.5\% (Tesfaye et al., 2012). One of Ethiopia National Strategic Plan for Malaria Prevention and Control $2011-2015$ is to maintain $100 \%$ of households in malarious areas own, on average, two LLINs (President's malaria Initiative, 2011).

There was wide gap between coverage and utilization of LLINs in Ethiopia. Some LLINs available in the household were not used (Tesfaye et al., 2012; Daddi et al., 2005; Ayalew and Amsalu, 2009). Not all ITNs freely supplied to households were used (Gashaw and Wakgari, 2008).

Malaria vulnerable groups, young children and pregnant women, should be prioritized to use ITNs available in the household (Jodi et al., 2010). Most nations in Africa have policies for distributing ITNs to pregnant women through various mechanisms; however coverage remains well below the targets (Megha et al., 2013). Some studies done in Ethiopia indicated proportion of pregnant women who sleep under ITNs the night preceding the studies were less than $50 \%$ (Tesfaye et al., 2012; Daddi et al., 2005). 5.5 lives could be saved per year for every 1000 children under 5 years of age protected by using ITNs (WHO, 2007). In Ethiopia, LLINs utilization rate of children under five years was less than 50\% (Sibhatu et al., 2012; Tesfaye et al., 2012).

This study was carried out to ascertain consistent delivery (owing) and utilization of LLINs in malaria endemic area of Gida Ayana district. As longevity of the net and longevity of insecticidal activity to retain its biological activity on LLINs guarantee for three years, LLINs need continuous replacement every three years to sustain malaria prevention in the community. In Gida Ayana district, LLINs have been used for malaria control since 2007 and the previous distributed old unusable LLINs have to be replaced with new ones to enhance the ongoing efforts to sustain and expand malaria intervention.

\section{MATERIALS AND METHODS Study Area and Period}

The study was conducted in malarious kebeles of Gida Ayana district in June 2013. Gida Ayana district is located $112 \mathrm{Kms}$ from Nekemte, which is the main city of East Wollega Zone. The district consists of 25 kebeles of which 8 are malarious.

\section{Sample Size Determination and Sampling Method}

A community based cross-sectional study was conducted in four Kebeles (Gutin 01 kebele, Andode-
Sci. Technol. Arts Res. J., April-June 2014, 3(2): 162-166

dicho, Tulu Lencha and Lelistu Anger) which were randomly selected using the lottery method from eight malarious kebeles of Gida Ayana district. The study units were households and the number of households which were included in the study in each selected kebeles was proportional to the total number of households in the kebeles (Table 1).

Table 1: Number of households sampled from selected malarious kebeles of Gida Ayana District.

\begin{tabular}{cccc}
\hline Kebeles & $\begin{array}{c}\text { Population } \\
\text { size }\end{array}$ & Households & $\begin{array}{c}\text { Households } \\
\text { sampled }\end{array}$ \\
\hline Gutin 01 & 7415 & 2484 & 118 \\
Lelistu Anger & 6929 & 1862 & 88 \\
Tulu Lencha & 4281 & 1040 & 50 \\
Andode-dicho & 15886 & 3454 & 164 \\
\hline \multicolumn{1}{c}{ Total } & $\mathbf{3 4 5 1 1}$ & $\mathbf{8 8 4 0}$ & $\mathbf{4 2 0}$ \\
\hline
\end{tabular}

Sample size was determined by using a single population proportion formula, by an expected proportion (ITN coverage) of $47.5 \%$ in Oromia (Estifanos et al., 2008), $5 \%$ margin of error, and $95 \%$ confidence of certainty. Considered a 10\% adjustment for non-response rate, the calculated sample size was 420 households. The households for the study were systematically (every $21^{\text {th }}$ of households) selected from the kebeles. Then, the heads of households (or their spouse) were interviewed. If the appropriate respondent was not available in the house during initial visit, revisits were considered to contact the appropriate person.

\section{Data Collection Methods}

Data were collected by using structured, pre-tested and interviewer administered questionnaire initially prepared in english and then translated to local language Amharic and Afan Oromo. In households where LLINs were reported to be present, interviewers checked and confirmed the presence of the bed nets in the sleeping area. Data were collected by four trained individuals, supervised by one supervisor.

The major variables included in the questionnaire were socio-demographic factors, LLINs owing, replacement of LLINs after three years of use and prioritizing available LLINs for pregnant women and children less than five years.

\section{Data Analysis}

Data entry and analysis were performed using SPSS 20.0 for windows software. Logistic regression analysis was used for determining LLINS ownership and sociodemographic characteristics. 95\% confidence intervals $(\mathrm{Cl})$ were used to examine the strength of association and $P$ values of less or equal to 0.05 were considered significant.

\section{Ethical Considerations}

The study was conducted after obtaining ethical clearance from Wollega University Ethical Review Committee (Ref. No: WU-RD/191/2013, Dated: 1/03/2013). Permissions were obtained from different administrative officials of the study area. Verbal consent was also obtained from the study participants before administering the questionnaire. 
Geletta Tadele et al.,

\section{RESULTS}

\section{Socio-demographic Characteristics}

Of the 420 households included in the study; total population of 2002 were identified of which $3.2 \%$ were pregnant women and $21.8 \%$ were children less than five years of age. Average \pm SD household size of $4.77 \pm 1.93$. The mean age of respondents was $30.2 \pm 9.3$. $76.2 \%$ respondents were female and $65.2 \%$ of respondents were illiterate (Table 2).

\section{LLINs Possession}

Of the 420 households included in the study, $69.3 \%$ possessed one or more long lasting insecticide treated nets which were owned for the $1^{\text {st }}$ time or replaced. Average LLINs possessed per household was 1.2. The attrition rate of LLINs possession was $24 \%$ (Table 3 ). There was no significant association between sociodemographic characteristics of respondent and LLINs owing $(P>0.05)$ (Table 4).

Of the 291 households which possessed one or more LLINs, $60.8 \%$ have replaced the long lasting insecticide nets after three years of use and $39.2 \%$ of households owned the bed nets primary (Table 5). Of 114 households who have possessed bed nets for the $1^{\text {st }}$ time, $70.2 \%$ have used the LLINs for more than three years. $57.8 \%$ of respondents knew as long lasting insecticide treated nets need replacement after 3 years of use (Table 6). $81.3 \%$ of respondent prefer free supply of bed nets for sustainable use of insecticide treated bed nets for malaria control (Table 5). There was no significant association between educational status and residence of respondents with knowledge of LLINs replacement every three years (Table 6).
Sci. Technol. Arts Res. J., April-June 2014, 3(2): 162-166

Table 2: Socio-demographic characteristics of respondents in malarious kebeles of Gida Ayana district, East Wollega Zone, Oromia, Ethioipa

\begin{tabular}{lcc}
\hline Variables $(\mathbf{n}=\mathbf{4 2 0})$ & Number & Percent \\
\hline Sex & & \\
$\quad$ Male & 100 & 23.8 \\
$\quad$ Female & 320 & 76.2 \\
\hline Ethnicity & & \\
$\quad$ Amhara & 248 & 59 \\
Oromo & 129 & 30.7 \\
$\quad$ Tigrae & 41 & 9.8 \\
$\quad$ Others & 2 & 0.5 \\
\hline Education Status & & \\
$\quad$ Literate & 146 & 34.8 \\
$\quad$ Illiterate & 274 & 65.2 \\
\hline
\end{tabular}

Table 3: Long lasting insecticide treated nets possession of households in Malarious Kebeles of Gida Ayana district, East Wollega Zone, Oromia, Ethioipa.

\begin{tabular}{ccc}
\hline Variables & Frequency & Percent \\
\hline LLINs possession & & \\
OwnedPrimary or replaced & 291 & 69.3 \\
Attrition & 101 & 24.0 \\
No bed nets & 28 & 6.7 \\
\hline Number of LLINs owed & & \\
1 & 237 & $81.4 \%$ \\
2 & 50 & $17.2 \%$ \\
3 & 4 & $1.4 \%$ \\
\hline
\end{tabular}

Table 4: Socio-demographic characteristics of respondents and long lasting insecticide treated nets possession in Malarious Kebeles of Gida Ayana district, East Wollega Zone, Oromia, Ethioipa.

\begin{tabular}{|c|c|c|c|c|c|c|}
\hline \multirow{2}{*}{ Variables } & \multicolumn{2}{|c|}{ LLINs Owing } & \multicolumn{4}{|c|}{ Logistic Regression Analysis } \\
\hline & Yes & No* & OR & DF & P- value & 95\% C.I. for OR \\
\hline \multicolumn{7}{|l|}{ Sex } \\
\hline Male & 66 & 34 & \multirow{2}{*}{0.82} & \multirow[b]{2}{*}{1} & \multirow{2}{*}{0.415} & \multirow{2}{*}{$(0.508,1.322)$} \\
\hline Female & 225 & 95 & & & & \\
\hline \multicolumn{7}{|l|}{ Residence } \\
\hline Urban & 87 & 31 & \multirow{2}{*}{1.344} & \multirow{2}{*}{1} & \multirow[t]{2}{*}{0.195} & \multirow[t]{2}{*}{$(0.86,2.1)$} \\
\hline Rural & 204 & 98 & & & & \\
\hline \multicolumn{7}{|l|}{ Education } \\
\hline Literate & 105 & 41 & \multirow{2}{*}{1.212} & \multirow{2}{*}{1} & \multirow[t]{2}{*}{0.394} & \multirow[t]{2}{*}{$(0.78,1.88)$} \\
\hline Illiterate & 186 & 88 & & & & \\
\hline
\end{tabular}

Table 5: Status of Long lasting insecticide treated nets possessed by households in malarious kebeles of Gida Ayana, East Wollega Zone, Oromia, Ethiopia.

\begin{tabular}{lcc}
\hline Variables & Number & Percent \\
\hline Status of bed nets $(\mathrm{n}=291)$ & & \\
Owned for the first time & 114 & 39.2 \\
Replaced & 177 & 60.8 \\
\hline Period of owning LLINs among for the $\mathbf{1}^{\text {st }}$ time possessed $(\mathrm{n}=114)$ & & \\
Less than 3 years ago & 33 & 30 \\
Before 3 years ago & 80 & 70 \\
\hline Knowledge of bed nets replacement after $\mathbf{3}$ years of use $(\mathrm{n}=391)$ & & \\
Freely supplied & 318 & 81.3 \\
Cost subsidize supply & 73 & 18.7 \\
\hline
\end{tabular}


Table 6: Educational status and residence of respondents with knowledge of LLINs replacement in malarious kebeles of Gida Ayana District, June, 2013

\begin{tabular}{ccccccc}
\hline \multirow{2}{*}{ Variables } & \multicolumn{2}{c}{$\begin{array}{c}\text { Knowledge of bed nets } \\
\text { replacement }\left(\mathrm{N}=391^{*}\right)\end{array}$} & \multicolumn{3}{c}{ Logistic Regression Analysis } \\
\cline { 2 - 7 } & Yes & No & OR & DF & P-value & 95\%C.I. for OR \\
\hline $\begin{array}{c}\text { Education status } \\
\text { Literate } \\
\text { Illiterate }\end{array}$ & 77 & 59 & & & & \\
\hline $\begin{array}{c}\text { Residence } \\
\text { Urban } \\
\text { Rural }\end{array}$ & 150 & 105 & 0.892 & $\mathbf{1}$ & 0.597 & $(0.585,1.36)$ \\
\hline & 72 & 40 & & & & \\
\hline
\end{tabular}

\section{Utilization of LLINs}

Of 291 households that owned one or more LLINs, any member of the household slept under a net the night prior to the study was $64.9 \% .51 \%$ of households use the available LLINs always. In $69.75 \%$ of households LLINs were hanged in the sleeping area (Table 7).
Twenty (43.1\%) of the 65 pregnant women identified slept under insecticide treated bed nets the night prior to the study. Of the 428 under five children identified during the study, $48.4 \%$ slept under insecticide treated bed nets the night prior to the study (Table 8).

Table 7: Utilization of LLINs in households in in malarious kebeles of Gida Ayana, East Wollega Zone, Oromia, Ethiopia.

\begin{tabular}{lcc}
\hline \multicolumn{1}{c}{ Variables } & Number & Percent \\
\hline $\begin{array}{l}\text { Sleeping pattern prior to the night of the study } \\
\text { Yes }\end{array}$ & 189 & 64.9 \\
No & 102 & 35.1 \\
\hline Frequency of using bed nets & 149 & 51 \\
$\quad$ Always & 137 & 47.2 \\
Intermittently & 5 & 1.7 \\
$\quad$ Not used & 203 & 69.7 \\
\hline Location of insecticide treated bed nets in households & 88 & 31.3 \\
$\quad$ In sleeping area & & \\
Not in sleeping area &
\end{tabular}

Table 8: Malaria risk groups and utilization of LLINs in in malarious kebeles of Gida Ayana, East Wollega Zone, Oromia, Ethiopia

\begin{tabular}{lcc}
\hline Variables & Frequency & Percent \\
\hline Slept under bed nets the night prior the study & 207 & 48.4 \\
Not slept under bed nets the night prior the study & 221 & 51.6 \\
\hline
\end{tabular}

\section{DISCUSSION}

Coverage of households owned at least one long lasting insecticide treated nets in the study area was $69.3 \%$. This coverage was low compared to study done in a rural area of Western Kenya which was 95\% (Githinji et al., 2010). But this finding was higher than the study conducted in Arbaminch Town and the malarious villages of Arbaminch Zuria District (58.8\%) (Ayalew and Amsalu, 2009) and it was Comparable to study done in Kersa, Eastern Ethiopia (65.5\%) (Tesfaye et al., 2012). Average LLINs per household in the study area was 1.2 which was lower than Ethiopia strategic plan to provide, on average, two ITNs per household in all malaria-risk areas (Ethiopian $\mathrm{MOH}, 2011$ ).

Attrition rate of households in LLINs was $24 \%$. These households lost the old unusable LLINs and they did not have LLINs in their houses during the study. So, every household in malaria endemic area should be considered during replacement of the LLINs to enhance recent efforts in malaria reduction.

Of 291 households which have one or more long lasting insecticide treated nets, $60.8 \%$ have replaced the bed nets after three years of use. LLINs have been replaced in the study area to sustain recent efforts exerted in malaria control. Out of 391 households which have LLINs and lost previously owned LLINs, 227 householders' respondents knew the need of LLINs replacement in every 3 years of use for consistent possession and utilization of LLINs. There was no significant association between educational status of respondents and knowledge of LLINs replacement. 81.3\% of households' preferred free supply of LLINs to cost subsidized supply to sustain utilization of LLINs as some of the respondents have economic problem and they do not have alternative of getting LLINs rather than free supply of LLINs from local government health organization.

Of 114 households who have possessed bed nets for the $1^{\text {st }}$ time; $70.2 \%$ have used the bed nets for more than three years. Hence, some households did not replace the old used nets during redistribution, the bed nets can be damaged/worn out/ and decreased insecticidal effect which can minimize the protection obtained from LLINs.

Of 291 households that owned one or more LLINs, any member of the household slept under a net the night prior to the study was $64.9 \%$. This utilization rate was lower as 
Geletta Tadele et al.,

compared to study done in Arbaminch area which was 73\% (Ayalew and Amsalu, 2009). It is higher than study done in Eastern Ethiopia Kersa (33.5\%) (Tesfaye et al., 2012) and Gursum district (21.5\%) (Sibhatu et al., 2012).

Proportion of pregnant women and under five children slept under bed nets the night preceding the study was 43.1 and $48.4 \%$ respectively. This finding was higher than the study conducted in Arbaminch area 35\% (pregnant women) and $40.3 \%$ (children $<5$ years) (Ayalew and Amsalu, 2009). Utilization rate in under five children in this study was lower than study done in Wonago which was $58 \%$ (Gashaw and Wakgari, 2008). Utilization of LLINs among malaria risk group is low. There is a need to have strategy for malaria risk group to increase deliver of bed nets and health information dissemination for effective use of LLINs available in the household.

\section{CONCLUSIONS}

In the study area, old (worn out) insecticide treated bed nets have been replaced after three years of use to sustain malaria control. Some households lost previously ownedLLINs and discontinue using the bed nets due to lack of replacement. Utilization of LLINs is low among malaria risk group. It is important to assess durability of LLINs in context of Ethiopia as a different factors that may affect physical intactness and insecticidal effect on LLINs. Health extension workers in malaria endemic area should consider every households during substituting the old unused LLINs by new once in the community.

\section{ACKNOWLEDGEMENT}

This work was fully supported by the grants from Wollega University (WU-RD-49105; Date: 03/03/2013. The authors gratefully acknowledge Teklu Merga, Gida Ayana, Malaria Control and Prevention expert for their support during the study.

\section{REFERENCES}

Anni-Maria, P., Claudia, W., Niklas, B., Jolene, S. (2012). Cost and cost effectiveness of long-lasting insecticidetreated bed nets - a model-based analysis. Biomedical Central 10: 5.

Ayalew, A. and Amsalu, F. (2009). Utilization of insecticide treated nets in Arbaminch Town and the malarious villages of Arbaminch Zuria District, Southern Ethiopia. Ethiopian Journal Health Development 23(3):206-215.

Batisso, E., Habte, T.,Tesfaye, G., Getachew, D., Tekalegne, A., Kilian, A., Mpeka, B., Lynch, C (2012). A stitch in time: a cross-sectional survey looking at long lasting insecticide-treated bed net ownership, utilization and attrition in SNNPR, Ethiopia. Malaria Journal 11:183.

Daddi, J., Gezahegn, T., Wakgari, D., Adugna, W., Daniel, K., Desta, A (2005). Baseline survey for the implementation of insecticide treated mosquito nets in Malaria control in Ethiopia. Ethiopian Journal of Health Development 19(1):16-23.

Erlanger, T.E., Enayati, A.A., Hemingway, J., Mshinda, H., Tami, A., Lengeler, C. (2004). Field issues related to effectiveness of insecticide-treated nets in Tanzania. Medical and Veterinary Entomology 18:153-60.

Estifanos, B.S., Teshome, G., Jeremiah, N., Patricia, M.G. Aryc, W.M., Paul, M.E., Yeshewamebrat, E., Tekola, E., Dereje, O., Asrat, W.M., Admas, T., Zerihun, T., Abate, T., Gedeon, Y., and Frank, O.R. (2008). Malaria
Sci. Technol. Arts Res. J., April-June 2014, 3(2): 162-166

prevalence and mosquito net coverage in Oromia and SNNPR regions of Ethiopia. BMC Public Health 8: 321.

Federal Democratic Republic of Ethiopia Ministry of Health (2004). Insecticide treated nets, National Strategic plan for going to scale with coverage and utilization in Ethiopia: 2004-2007.

Federal Democratic Republic of Ethiopia, Ministry of Health (2006). National five-year Strategic plan for malaria prevention \& control in Ethiopia, 2006-2010. www.cdbph. org/.../who_evipnet_documents_guideline_Ethiopia

Federal Republic of Ethiopia Ministry of Health (2007). Ethiopia National Malaria Indicator Survey 2007: Technical Summary.[cited 2013; may 18]; Available from www.cartercenter.org/.../malaria/Ethiopia_2007_MIS

Federal Democratic Republic of Ethiopia Ministry of Health (2011). Malaria Prevention andControl Program.

Gashaw, D. \& Wakgari, D. (2008). Knowledge \& utilization of insecticide treated Mosquito nets among freely supplied households in Wonago Woreda, Southern Ethiopia. Ethiopian Journal of Health Development 22(1): 34-41.

Githinji, S., Herbst, S., Kistemann, T., Noor, A.M. (2010). Mosquito nets in a rural area of Western Kenya: ownership, use and quality. Malaria Journal 9:250.

Jodi, L.V., Julie, T., Adam, W., Manisha, A.K., Ayub, M., Marcy, E., Allen, H., and Laurence, S. (2010). Assessing bed net use and non-use after long-lasting insecticidal net distribution: a simple Framework to guide programmatic strategies. Malaria Journal 9: 133.

Kilian, A., Byamukama, W., Pigeon, O., Gimnig, J., Atieli, F., Koekemoer, L.L., Protopopoff, N (2011). Evidence for a useful life of more than three years for a polyester-based long-lasting insecticidal mosquito net in Western Uganda. Malaria Journal 10:299.

Megha, S., Graham, B., Stephen, J.R. (2013). Ownership and use of insecticide-treated nets during Pregnancy in subSaharan Africa: a review. Malaria Journal 12:268.

President's Malaria Initiative (2010). Malaria operational plan for Ethiopia fy 2011. [cited 2013; June 22].

Sibhatu, B., Ayalu, R., Haji, K. (2012). Insecticide-Treated Bed Nets for Malaria Control in Eastern Ethiopia. Journal of Tropical Medicine Article: ID 235015.

Tesfaye, G., Yemane, B., Alemayehu, W. (2012). Low longlasting insecticide nets (LLINs) use among household members for protection against mosquito bite in Kersa, Eastern Ethiopia. BMC Public Health 12:914.

WHO, Insecticide-treated mosquito nets (2007). A WHO position statement: (cited 2013; march 25); Available from www.who.int/malaria/publications/atoz/itnspospaperfinal/.. .index.ht

World Health Organization (2010). MDG 6: combat HIV/AIDS, malaria and other diseases. (cited 2013, June 12); Available from http:/www.who.int/topics/millenniumdevelopment-goals/diseases/en/index.html

WHO (2005). Communicable disease control, prevention and eradication WHO pesticide evaluation Scheme). Report of the meeting on the development of guidelines for testing and evaluation of long-lasting insecticidal mosquito nets. (c2013; June 12); from http://www.who.int/whopes/gcdpp

WHO (2012). World Malaria Report 2012 FACT SHEET. [2013; May 22]; Available from www.who.Int/malaria.

World malaria report (2005). (2013; march 22); Available from http://www.rbm.who.int/wmr 2005/html/2-1htm. 